\title{
Subjetividad y separación. La crítica del joven Hegel a la separación de facultades y a la soledad ontológica.
}

\author{
JUAN J. PADIAL \\ Universidad de Málaga
}

Hegel quiso ser pastor protestante. Por ello se trasladó, en octubre de 1788, de su ciudad natal, Stuttgart, a la Fundación protestante de Tubinga, donde realizó estudios eclesiásticos y universitarios que lo habrían encaminado al ministerio reformado. En 1790 comenzó su formación en la Facultad de Teología. Tan sólo tres años más tarde, en septiembre de 1793 realizó, de nuevo en Stuttgart, el examen fin de carrera ante el consistorio eclesiástico. Al solicitar ante las autoridades eclesiásticas un adelanto en la fecha del examen, con el motivo de poder viajar y establecerse en Suiza como preceptor privado, mostraba claramente su renuncia a cualquier aspiración clerical. Un mes más tarde partiría para Berna a la casa del patricio Carl Friedrich Steiger. Del hecho de que jamás se ordenase, del aroma crítico que destilan los primeros escritos del joven, y de la orientación a las realidades sociopolíticas con que tratan otra porción de estos primeros escritos, algunos ${ }^{1}$ han deducido la ausencia de una genuina y sincera religiosidad en la vida del seminarista de Tubinga. Como mostró con suma perspicacia Küng ${ }^{2}$ esta afirmación contradice tanto muchos hechos biográficos del joven Hegel, como lo que se puede extraer limpiamente de muchos de los textos.

Es célebre el enfrentamiento de Walter Kaufmann con Richard Kroner y con Thomas Malcolm Knox sobre los Escritos Teológicos de Juventud. Pugna que en última instancia se dirige, como es obvio, contra Herman Nohl y su maestro Wilhelm Dilthey. Tiene razón Kaufmann en que la religiosidad no se identifica con la teología; precisamente en ello estriba la distinción entre religión objetiva y

1 Cfr.: Lacorte, Il primo Hegel, Sansoni, Pubblicazioni dell'Istituto di Filosofia dell'Università di Roma, VII, Florencia, 1959; Negri, A., Stato e diritto nel giovane Hegel. Studia sulla genesi illuministica Della filosofia giuridica e politica de Hegel, Padua, 1958

2 Küng, H., La encarnación de Dios. Introducción al pensamiento teológico de Hegel como prologómenos para una cristología futura, Herder, Barcelona, 1974, p. 51. 
subjetiva que articula Hegel. Pero ello no autoriza a sostener ni que los Escritos de Juventud respondan a una fase antiteológica, como sostiene Kaufmann ${ }^{3}$, ni a declarar como Kroner, que Hegel se encaminase por los derroteros de una "mística cristiana que busca la adecuada expresión especulativa" resulta innegable el énfasis crítico de tales escritos, tal criticismo se pone en relación con la distinción entre concepto y abstracto, pues lo peculiar del ataque a la teología recibida es su caracterización como abstracta, la distancia en la que considera y avista lo divino. De aquí que en estos Escritos de Juventud esté Hegel ya entero, al menos en inspiración. "Es clara en la obra de Hegel la presencia recurrente de temas constantemente reelaborados, y desarrollados en varios registros, que constituyen, a la vez, la materia de su larga meditación y el hilo conductor, sin solución de continuidad, de su trayectoria intelectual"5. Por ello estos escritos no se comprenden suficientemente bajo el prisma del desarrollo intelectual, o del ideal de juventud -el educador moral, al modo de Lessing - , que años más tarde, en Jena se abandonará. El énfasis crítico está al servicio de una depuración teológica, o de un discernimiento especulativo con claro alcance religioso. No se trata por tanto de una mera pars destruens, sino la presentación de unos temas - lo abstracto, el dualismo, la oposición no conciliada, la negación, la no distinción de facultades, la libertad, la conciencia desgraciada, el papel de las instituciones-, que Hegel meditará y desarrollará a lo largo de toda su vida.

Conviene tomar en serio el enfoque y la perspectiva de Dilthey, y discernir el tema de la religiosidad hegeliana, que por otra parte es bien complejo. Desde aquí se advierte que su crítica más bien "comporta un replanteamiento del tema de Dios, no una vacilación o una crítica de fondo dirigida la tema mismo" ". Replanteamiento que es congruente con la renuncia a su carrera con pastor, pero no en el modo del establecimiento de una ruptura, sino en el de una experiencia de la conciencia, de una ampliación del mundo en que se vive, y una maduración de la subjetividad. Punto este que se relaciona con la amarga experiencia vital de su paso por el seminario de Tubinga y la amistad entablada con Hölderlin y Schelling, quienes tuvieron las mismas vivencias y también se decidieron por la vocación filosófica, más que por la clerical. Sostengo con Leonardo Polo ${ }^{7}$ que el tema de la religiosidad es nuclear para la comprensión

3 Cfr.: Kaufmann, W. A., "Hegel's Early Antitheological Phase", The Philosophical Review, vol. 63, no 1, Enero de 1954, pp. 3-18.

4 Kroner, R., "Introduction" en Hegel, Early Theological Writings, University of Pennsylvania Press, 1971, p. 8.

5 Polo, L., Hegel y el posthegelianismo, Eunsa, Pamplona, 1985, 1999 ( $2^{\mathrm{a}}$ edic.), p. 177.

6 Polo, L., Hegel y el posthegelianismo..., p. 214.

7 Polo, L., Hegel y el posthegelianismo..., Cfr.: el capítulo III de la tercera parte titulado: 
de la antropología hegeliana. Precisamente por ello, conviene introducirse en él, e inquirir larga y despaciosamente en los fragmentos y documentos que se conservan del joven Hegel.

En este artículo pretendo examinar la primerísima producción editada de Hegel. En 1792 aún en Tubinga, y un año antes de comenzar el trienio teológico, "comienza a escribir los fragmentos Volksreligion und Christentum (Religión del pueblo y Cristianismo)"8. Entre 1794 y 1795 redacta una serie de Fragmentos Republicanos. Además están disponibles algunos extractos de lectura y la correspondencia con sus dos grandes amigos del seminario. $\mathrm{He}$ tratado en otro lugar de la Vida de Jesús ${ }^{9}$ escrita poco antes. Dejo para otra ocasión los demás escritos de su estancia en Berna. Estos escritos juveniles, que comienzan con los fragmentos conservados de este Ensayo de Tubinga, están escritos desde el claro convencimiento de la compatibilidad entre razón y religión. Convencimiento, que en lo que atañe a la "religión privada", está en la línea del racionalismo de Semmler y de su maestro Baumgarten, y por lo tanto de la línea especulativa que impregnaba la formación de los jóvenes aspirantes a pastores en el Tubinga de aquel entonces. Así, el descubrimiento de la distinción concepto-abstracto equivale, como mostraré, a la comprensión - y reformulación - , por parte de la poderosa mente de Hegel, de la Ilustración alemana, y lo acontecido en ella.

Los años de formación teológica en la Stift (fundación) de Tubinga, y el trato de sus preceptores dejarán su huella. Impronta que tiene carácter más conceptual que psicológico, pues "todo lo que en Tubinga se piensa y hace en filosofía pasa por un diálogo, y frecuentemente por un debate, con Kant"10. Este influjo es decisivo, y se manifestaba en las filias y fobias respecto a la formación recibida en el seminario. Ya en la aversión al tipo de teología supernaturalista, pero que se pretendía libre del ataque kantiano, impartidas por Flatt y Storr; ya en la crítica también en clave kantiana a tal teología realizada por Karl Inmanuel Diez, uno de sus tutores en el seminario ${ }^{11}$. Fueron años de trato intenso con Hölderlin y con Schelling, de esperanzas políticas que se disparan con los cañonazos revolucionarios en Francia, y de discernimiento

"La religiosidad hegeliana como fuente de la interpretación especulativa del tiempo", pp.: 214231.

8 Ripalda, J. M., "Cronología del joven Hegel” en EJ, 33.

9 Padial, J. J., "El llanto más acerado. Sobre la distancia y la profundidad en los escritos de juventud hegelianos" en Thémata. Revista de Filosofía, n³9, Universidad de Sevilla, Sevilla, 2007.

10 Paredes, M. C., Génesis del concepto de verdad en el joven Hegel, Universidad de Salamanca, Salamanca, 1987, p. 33.

11 Cfr.: Henrich, D., Konstellationen: Probleme und Debatten am Ursprung der idealistischen Philosophie (1789-1795), Klett-Cotta, Stuttgart, 1991. 
religiosamente íntimo, que se entrevera con las lecturas y las conversaciones con sus compañeros de cuarto, Hölderlin y Schelling. Sin la resistencia de los tres amigos al tipo de formación teológica recibida en Tubinga de manos de Storr, y sin las aporías que la Doctrina de los postulados les suscitaba, no cabe comprender la dirección de los primeros pasos de Hegel.

\section{UNA PROFUNDA NECESIDAD DEL ESPÍRITU HUMANO}

Cuando Kant redacta la Crítica de la razón práctica, tiene en mente una "necesidad subjetiva, y no obstante, verdadera e incondicional de la razón"12. Estas palabras debieron de dejar muy pensativo a Hegel, porque parecían que se encaminaban en la misma dirección que sus intereses especulativos durante el internado en Tubinga. Esta necesidad es para Kant, subjetiva, y por lo tanto no dice relación ni a objetos teóricos, ni a fenómenos algunos. Se trata de la necesidad de comprender los hechos morales, con su universalidad, pureza y absolutez. Pero tal comprensión no es teórica u objetiva, sino subjetiva. Los hechos morales postulan, exigen, unos supuestos, no teóricos, ni especulativos, que no obstante se imponen al conocimiento teórico, por ejemplo que existan causalidades libres, comienzos independientes de series causales, al margen de una única legalidad natural; o la existencia del reino leibniziano de la gracia: la vida futura y Dios. Sin estos postulados "se nos tornarían vanas quimeras las leyes morales"13.

El imperio de la razón práctica viene a equivaler para Kant a la separación de la conducta moral respecto de los impulsos y tendencias sensibles. La moralidad y pureza de las acciones se vería comprometida si se actuase por mor de la satisfacción de impulsos sensibles o como un medio para conseguir algo otro que la acción moral. Kant tiene en mente, al redactar la Crítica de la razón práctica, tanto el eudemonismo como el utilitarismo ético de la Ilustración inglesa. El adversario es el empirismo inglés, porque le parece que disuelve la necesidad absoluta de las leyes morales. La actuación moral ha de ser pura, absoluta, y en ello consiste el único interés de la razón pura práctica. De aquí que para Kant, la ley no sea algo empírico, sino el único Faktum de la razón pura. Pero entonces Kant constata un abismo entre la razón y la sensibilidad, entre el mundo inteligible y el mundo sensible.

"Este deber expresa una acción posible, cuyo fundamento no es otra cosa que un simple concepto, mientras, por el contrario, el principio de una acción de la naturaleza es siempre un fenómeno... Por muchas que sean las razones naturales que me impulsan a querer, por numerosos que sean los móviles sensibles, no pueden producir el deber, sino sólo un querer que está muy lejos de ser necesario, que por 
el contrario siempre es condicionado, mientras el deber que pronuncia la razón impone norma y fin, más aún prohibición y respeto"14.

Así es como Kant separa el ámbito de la libertad del de la naturaleza, el de la moralidad del de la antropología, el de lo absoluto del de lo condicionado, el de lo puro del de lo empírico. Y esta separación no es una mera inconexión de estas esferas, sino una oposición entre ellas, en cuanto su sujeto es el hombre. En cuanto fenómeno, el hombre se encuentra sometido a las condiciones necesarias del tiempo, - al enlace causal de los sucesos en el tiempo-, pero en cuanto cosa en sí, solo se somete a las leyes que él mismo se da mediante la razón. Es así como esta oposición extrema la separación y la soledad ontológica del hombre. No encuentra en el mundo nada parecido a sí, pero tampoco precisa remitirse a un origen con el que estuviera religado. "En vez de concebir su dignidad como un trasunto de la suprema dignidad divina, el hombre la reivindica desde sí mismo para sí. Ha dejado de ser un don gracioso que se acepta, para convertirse en algo que se conquista en la autoafirmación"15. El enfoque de la religión, por tanto, será el de una pura religión de la razón, o el de una religión del mundo inteligible.

La tematización de Dios por Kant es sumamente respetuosa con la índole de la moralidad pura. Dios es un postulado de la razón pura en su uso práctico; es la condición de posibilidad de lo exigido por una vida que se ha dignificado en el cumplimiento del deber por el deber, no por recompensa alguna. Tal respeto de la acción moral exige ser coronado con la felicidad, que resulta absolutamente imposible en el orden de la naturaleza conocida fenoménicamente. El hombre no tiene el poder que se requeriría sobre las condiciones naturales e históricas para darse a sí mismo tal galardón. Y por lo tanto la conducta moral postula la existencia de una razón suprema - summun rationale - , fundamento de la naturaleza, y que se conduce también por leyes morales — summum bonum-. Mas entonces sucede que la felicidad - que pertenece al ámbito fenoménico- es una consecuencia de la moralidad, el efecto debido, que se cumple en el mundo inteligible. "La exacta concordancia entre la felicidad y la moralidad" 16 , entre dos ámbitos escindidos, postula - como moralmente necesaria - la existencia de Dios. La autoafirmación y la soledad alcanzan una nueva cota.

Pero avistar a Dios como postulado, necesariamente equivale a suponerlo, a hacer de él un requisito, una condición necesaria. Y para Hegel esto equivale a situar a Dios en un más allá, a separarlo, o a considerarlo abstractamente. Dios es admitido como un supuesto, y sin embargo es una necesidad de la razón, que caracteriza la fe racional. Ésta consideración de lo divino era bastante frecuente

14 Kant, I., $K r V$, B 575 ss.

15 Llano, A., Fenómeno y Trascendencia en Kant, Eunsa, Pamplona, 1973, p. 302.

16 Kant, $A k ., \mathrm{V}, 125$. 
en la Ilustración, y fue la que recibió Hegel en sus años de formación como seminarista. No cabe que la teología tenga alcance especulativo, puesto que la metafísica postulativa solo tiene un alcance práctico. Se sabe de la realidad objetiva de Dios, alma y mundo inteligible, pero no hay modo de predicar conceptualmente de tales objetos. Aunque la moral no tiene necesidad ni de teologías, ni de religión, no obstante conduce a la religión. A una religión dentro de los límites de la razón, a un sistema racional, o una religión de la razón. El mismo Kant explica las que para él eran los dos únicos modos posibles de realizar una teología, el de los deístas y el de los teístas.

"quienes aceptan solamente una teología trascendental son llamados deístas; quienes admiten asimismo una teología natural son llamados teístas. Los primeros admiten que podemos conocer la existencia de un ser originario exclusivamente mediante la razón, pero sostienen que nuestro concepto de tal ser es solamente trascendental, es decir, el concepto de un ser que posee toda la realidad, pero que no podemos determinar de ninguna manera más específica. Los últimos afirman que la razón es capaz de determinar su objeto más precisamente por medio de la analogía con la Naturaleza, esto es, como un ser que contiene en sí mismo, por medio del entendimiento y la libertad, el principio último de todas las demás cosas. Así el deísta representa este ser meramente como causa del mundo (sin que pueda decirse si es por necesidad de su naturaleza o por libertad); el teísta, como autor del mundo" 17 .

Deismo y teismo estaban muy presentes en las clases de Teología en Tubinga en tiempos de Hegel. La teología natural de Reimarius aceptaba de Kant y del deísmo la identificación del summum bonum con el summun rationale. Lo mismo sucedía con la teología iluminística de Semmler, que hacía inútil la revelación para la noticia de Dios. El tribunal de la razón ha de discernir en el contenido revelado, según Semmler, por lo que es preciso realizar una crítica histórica que depure su mensaje. Semmler establece por tanto las bases de una Privatreligion, de una religiosidad privada, vinculada al libre examen que de las escrituras ha de hacer el creyente, desvinculada correlativamente de la dogmática de la iglesia a que institucionalmente se pertenezca. Así en Semmler aparecen los dualismos religión púbica / religión privada, y teología / religión. Estos dos binomios son relevantes ya en el Fragmento de Tubinga hegeliano, quien más tarde considerará la positivización del Cristianismo como el miembro público del primer binomio.

El segundo miembro del binomio, la religión privada, tenía su correlato en la cultura alemana del siglo XVIII, donde se había difundido ampliamente el pietismo. Los Pia Desideria (1675) de Philipp Jacob Spener fueron el brote 
primero del movimiento pietista. 'Vivir como cristianos' al margen de cualquier autoridad eclesiástica establecida que impusiese una determinada concepción dogmática. No debe parecer extraño que Kant abrazase de sumo grado el pietismo establecido, y no solo por haber sido educado de niño en él, sino por la autoafirmación que implica su teoría de la moralidad. Y es que el pietismo entró en profundas tensiones con la iglesia luterana. $\mathrm{Y}$ esto por su ataque decidido a la sola fides. Si pietismo y religión privada van de la mano, entonces la fe es superflua. La salvación es asequible a la vida de cualquier hombre. Solo las obras, la moralidad. Y aquí de nuevo vuelven a encontrar eco las famosas palabras de la Crítica de la razón práctica: lo único bueno sin restricciones en el mundo es la buena voluntad.

En Tubinga, en un ambiente universitario, donde los logros de la crítica kantiana eran irrenunciables por una parte, y por otra, donde también era irrenunciable la religión luterana, la solución académica forzosamente había de ser de compromiso. Y el adalid intelectual de esta negociación entre pietismo y luteranismo fue Storr. Küng explica el derrotero que Storr imprimió a la teología luterana hacia el teísmo. "Storr acude a un tercer procedimiento: en lugar de apoyarse en Aristóteles, como lo habían hecho la ortodoxia luterana del siglo anterior y la escolástica católica del barroco, en lugar de buscar refugio en Leibniz y Wolf, como lo hicieran los ilustrados Bilfinger y Canz, al igual que ciertos teólogos católicos de la época, Storr, en un sorprendente giro, se vuelve hacia Kant y Fichte. Storr piensa que basta con ver en una recta perspectiva la crítica trascendental de la razón pura, llevada a cabo por Kant, para que quede completamente claro que la pura razón es incompetente, que se mueve fuera de sus límites, cuando pretende hacer cualquier afirmación, positiva o negativa, sobre la verdad de la religión revelada. Con relación a la autoridad de la Escritura la única postura correcta de la razón es guardar silencio"18. Así se restablece la dogmática luterana al precio de que cualquier voz humana debe callar porque la mente desfallece. La abstracción y lejanía de Dios se hacen infinitas. Lo problemático y forzado de esta conciliación salta a la vista en cuanto se leen los textos kantianos. Lejos de guardar silencio Kant apostará porque "finalmente reine sobre todos la pura religión racional"19.

\section{LA CRÍTICA HEGELIANA A LA SEPARACIÓN DE FACULTADES}

En la última época de su formación universitaria Hegel se encontraba ante una aguda dificultad teórica y vital. De una parte le resultaba innegable e inmediata la vivencia pietista de la fe, que se ligaba a la comunidad y al sentimiento. Convencimiento que expresaría como:

18 Küng, H., La encarnación, 61.

19 Kant, I., La religión dentro de los límites de la simple razón, Ak., VI, 121. 
"una creencia capital dentro de la comunidad cristiana..., cuya enseñanza se reduce al amor insondable de Dios, hacia el cual todo tiende, y a la idea del Dios cercano y presente, que produce cuanto nos sucede" 20 .

Cercanía que tiene su correlato objetivo en la presencia de la religión en los más señalados momentos de la vida, como lo son el nacimiento, el matrimonio o la muerte ${ }^{21}$. Cercanía por tanto ligada a la comunidad, a un sentir común - sensus communis - en la acepción kantiana de la Crítica del juicio; y por tanto cercanía que está ligada a la comunicación intersubjetiva, a la cultura en que se crece, y a las prácticas en el seno de la misma. No es experimientada tal cercanía como fruto de una conclusión especulativa, sino de modo inmediato y práctico $^{22}$. Por ello, no es éste un texto ingenuo, mero retrato de la piedad popular, desvinculado así del ejercicio crítico y de la mayoría de edad racional. Por el contrario, la apreciación de que la creencia en un Dios presente, cercano, no situado allende el hombre, sino de que en su trascendencia es interior al hombre hunde sus raíces también - recuerdese a Kant - en una profunda "necesidad del espíritu humano"23.

Esta necesidad de la cercanía parece ordenar los ejercicios intelectuales de Hegel, quien por aquel entonces estaba sumamente concentrado en el desarrollo de la metafísica postulativa kantiana ${ }^{24}$. Esfuerzos suyos y de sus ilustres compañeros de habitación, alentados por Diez, que concluirían con la redacción de la celebérrima nota que es El más antiguo programa de sistema del idealismo alemán. Años más tarde, en una carta del 30 de agosto de 1795 a Schelling le confía:

"Estuve pensando un tiempo en escribir un ensayo para aclararme lo que puede significar acercarse a Dios, y pensé poder satisfacer así los postulados de la razón práctica, especialmente al de que ésta impere sobre el mundo de los fenómenos. Lo que yo presentía oscura y embrionariamente me lo ha iluminado tu obra del modo más magnífico y satisfactorio" 25 .

Y esto fue precisamente lo que chocó extraordinariamente al joven Hegel, que ve en la religión, en el "acercarse a Dios", el modo de suturar tal escisión

20 Nohl, H., Hegels Theologische Jugendschriften. Cit.: N y número de página: N, 22; fragmento: "Religión del pueblo y cristianismo".

21 Cfr.: N., 3

22 Cfr.: Choza, J., Los otros humanismos, Eunsa, Pamplona, 1994, pp. 105-121.

23 N., 3-4.

24 Dusing, K., "Die Rezeption der kantischen Postulatenlehre in den fruhen philosophischen Entwurfen Schellings und Hegels", en Das alteste Systemprogramm, Bubner, R., (ed.), Bonn, 1793.

25 Hegel, G.W.F., Escritos de juventud, Fondo de Cultura Económica, México, 1978, 1998 (2ª edición), p. 65. Cit: EJ. 
que rompe al hombre por dentro. Sorprende que Hegel ponga en relación la metafísica postulativa con las prácticas humanas, en las que los hombres marcan sus calendarios con días festivos, de carácter religioso, y señalan los momentos decisivos de sus vidas con actos de profundo valor simbólico, sociocultural y religioso. Estas son las prácticas por las que los hombres se acercan a Dios, y que Hegel intenta explícitamente comprender, según le confiesa a Schelling.

El propio Kant también se encontrará meditando al final de su vida, en el Opus postumum, qué signifique que la razón práctica impere sobre el mundo de los fenómenos. Justamente una pregunta que atenazará a Hegel por 1795. La solución del regiomontano es sorprendente, porque anticipa parcialmente el monofisismo hegeliano. En esta obra, Kant no hace de Dios un ser separado del hombre, sino "la pura razón práctica personificada con sus fuerzas motrices propias que dominan los seres del universo y a sus fuerzas" ${ }^{26}$. El problema para Hegel será si la razón práctica puede identificarse con la moralidad.

La vivencia religiosa inmediata y prerreflexiva de los hombres y mujeres parece no separar el móvil sensible del respeto a la ley moral. Estas prácticas conciliarían según Hegel razón y tendencias, la pureza de la moralidad no sería extraña a las razones naturales que impulsan a querer. Y esto es lo que Hegel encontró en los escritos de Schelling, una naturaleza (y en el hombre unos impulsos, tendencias y móviles) que ya es racional, pero que aún no sabe de sí, una razón que impera sobre el mundo de los fenómenos, sin necesidad de postular un mundo más allá, un reino de la gracia. Estos pensamientos de Schelling tenían suma importancia para Hegel, pues el problema radicaba en la tesis racionalista de la separación y mutua extrañeza de lo racional y lo sensible. Hegel detecta que la posición separada de la razón lleva a condenar las pasiones, sentimientos e inclinaciones, - o en la terminología de Hegel, al corazón y la imaginación - . Aquí aparece por primera vez la distinción entre concepto y abstracto, pues la moralidad kantiana es comprendida como un caso de abstracción, que exige el papel de un concepto adecuado de lo moral y la religión. Es el tema de la distinción entre religión objetiva - abstracta, muerta - , y religión subjetiva - donde el concepto, que exige la unificación entre fantasía, corazón y entendimiento, es entendido como la naturaleza en la que los diferentes seres vivos no son aislables, sino que conforman un sistema, el ecológico, o el libro de la naturaleza, en sus palabras - .

La racionalista e ilustrada condena de las pasiones no es tan solo un ejercicio teórico, porque cuando la razón no llega a los impulsos, tendencias y afectos, estos no por ello dejan de actuar o dejan de hacerse sentir. Simplemente actúan sin dirección, y por ello pueden entrar en colisión con lo que el ser humano se propone reflexivamente. Según Kant, actuarían de acuerdo con una inclinación 
ínsita al mal, que el denomina el mal radical. Hegel no es tan pesimista, sino que advierte la plasticidad y relativa autonomía de las tendencias. Sin la dirección de la razón la autorrealización en el plano psicológico se trunca. El conflicto entonces emerge y desgarra existencialmente; no es tan solo un problema teórico, sobre los supuestos exigidos por la presencia en la subjetividad del hecho moral. En la vivencia del conflicto consigo mismo de quien actúa aplicando las máximas de los tratados de moral ${ }^{27}$, Hegel advierte la tremenda repercusión en la subjetividad de la moralidad kantiana. Quizá sea este el primer texto sobre la conciencia desgraciada, y que permite afirmar que Hegel no comparte sin más el agudo criticismo de la Ilustración. Su actitud no es la del desembarazarse de un fardo, la conciencia moral, sino la de suturarla, curarla. Más que crítica, su actitud es terapéutica, y por lo tanto casi diríase que guiada por un elemento compasivo. "El carácter existencial de esta actitud proviene de que las oposiciones afectan a la vivencia de sí mismo, que no está al margen de ellas, sino íntimamente desgarrada" 28 . Parafraseando a Juan Ramón Jiménez, podría decirse de la pura razón práctica lo que este poeta señala del mar: "iqué sin ti estás, qué solo, / qué lejos, siempre, de ti mismo!, y de la relación entre la razón y la sensibilidad, lo que el mismo poeta expresa respecto al mar y las olas: "Abierto en mil heridas, cada instante, / cual mi frente, / tus olas van, como mis pensamientos, / y vienen, van y vienen, / besándose, apartándose, / con un eterno conocerse, / mar, y desconocerse" 29 .

Entre las lecturas de Hegel, una de las más influyentes, quizá fuese la del conde de Shaftesbury, quien había insistido en la relevancia para la autorrealización de virtudes que son intrínsecamente sociales, o que no se dan al margen de la comunidad, por ejemplo la elegancia y agrado en las relaciones sociales, la politeness. Shaftesbury le permitía a Hegel tematizar la no separación de las facultades, pues en el comportamiento polite, en la compasión, la simpatía o la confianza y amistad, se muestran capacidades humanas imposibles de conseguir si se extrema la separación entre las facultades. Hegel admira tal conjunción entre las facultades en caracteres como los de María Magdalena, donde su confianza y amor es inseparable del conocimiento que tiene de sí. Tales excelencias implican un saber conducirse, una sabiduría moral en el ámbito de las relaciones intersubjetivas, y por lo tanto en un ámbito que no se define por la necesidad de la acción, sino sobre lo que puede ser de otro modo y depende de nosotros, como diría Aristóteles.

La moralidad kantiana tan solo podría proporcionar en tales circunstancias una regla que habría que aplicar. Pero tal regla implica ya, a priori, un saber

27 N., 12.

28 Polo, L., Hegel y el posthegelianismo..., p. 182.

29 Jiménez, J. R., Diario de un poeta recien casado, 1 de febrero, "Soledad". 
qué hacer, no un saber que se logra en el propio conducirse, y por lo tanto inseparable de la experiencia, del error y su corrección ${ }^{30}$. De aquí que la sabiduría, tal y como la articula Hegel en Tubinga, "supone la incorporación de la experiencia, no como captación de lo puramente inmediato, sino como modo de conocimiento, a partir del cual se configura la conciencia" 31 . Moralidad no se identifica con sabiduría moral, porque esta última implica la flexibilidad de la phrónesis aristotélica; no es posible sin la estrecha cooperación entre las facultades cognoscitivas, e implica un constante ajuste del saber de sí y del saber del mundo. El frío entendimiento analítico o la sola dotación sensible son incapaces de dar razón de la conducta compasiva, del penetrar en el alma del otro que se logra mediante la simpatía, o del discernir sus conflictos y vivencias. Los fenómenos de la comprensión del otro, de su lenguaje, su comportamiento y expresión son algo imposible de realizar en terminos analíticos, cartesianos, pues implican una poderosa - y experiencial - articulación entre razón y sensibilidad. La experiencia de la conciencia, y con ella, la conciencia desgraciada, es lo que está aquí ya operativo.

La no separación de facultades y el carácter intersubjetivo de la excelencia humana es subrayada por Hegel ya en sus primeros escritos, donde parece enfrentarse decididamente al concepto de pura religión racional. Así en el Fragmento de Tubinga, parece despedirse de Semmler, Storr y del mismísimo Kant, cuando señala que:

"Pertenece al concepto de religión el no ser un puro saber sobre Dios, sus atributos y la relación nuestra y del mundo con él, así como acerca de la supervivencia de nuestra alma; saber que nosotros adquiriríamos o por pura razón o por otro procedimiento. La religión no es un mero conocimiento histórico o basado en el razonamiento; lo interesante en ella es que pone en juego el corazón, que influye en nuestros sentimientos y en la determinación de nuestra voluntad"32.

Es evidente el ataque a la Ilustración alemana en este fragmento. Frente al la religiosidad como saber dogmático o crítico de lo divino, la promoción integral de lo humano. No cabe que la religiosidad sea patrimonio del entendimiento, porque ninguna metafísica postulativa puede transformar los principios teóricos en acciones concretas, si estas no se reducen a la mera aplicación mecánica de reglas ya conocidas. Si se pretende lo contrario, entonces el imperativo categórico se transforma en un más allá de las tendencias, las inclinaciones y el corazón. Más allá que rige sobre ellas como un déspota. Será por ello que, años más tarde,

30 Cfr.: Vicente Arregui, J., "Sobre el gusto y la verdad práctica” Anuario Filosófico 23/1 (Universidad de Navarra 1990), págs. 163-176

31 Paredes, M. C., Génesis del concepto de verdad..., p. 37.

32 N., 5. 
ya en Francfort, Hegel comience a tematizar, a instancias de Hölderlin, el amor como lo que concilia libremente la tendencia con el deber, la subjetividad con la objetividad que antes dominaba solitaria y desnuda, abstracta en suma. Y es que como ha señalado María del Carmen Paredes, es preciso distinguir entre el amor a sí mismo, tendencia fundada en el entendimiento y por lo tanto en la objetividad, del amor como principio universal de la acción, que dice relación al otro, es inseparable de la vivencia intersubjetiva, y cuya intencionalidad no es cognoscitiva, porque el otro es el fin, y no la propia subjetividad. Tal distinción ya es operativa en el Manuscrito de Tubinga ${ }^{33}$. Aquel dominio de la razón solitaria sobre las tendencias e impulsos, viene a ser para Hegel el paradigma de una oposición no conciliada, la oposición entre lo psicológico y lo metafísico en el ser humano, y por lo tanto, cuando se presume la validez de una ética tal, entonces se ha conseguido un instrumento de dominio, que por otra parte se revela a la postre ineficaz, por cuanto no es suficientemente realista ${ }^{34}$, ya que no considera todos los factores que entran en juego.

En cualquier caso, Hegel está asignando a la religión el papel de mediación entre los sentimientos, el corazón y la voluntad pura. Aquí aparece no sólo una crítica a la religión de la razón, sino el descubrimiento de un universal, la religión popular, en el que se suturan las contradicciones de la pura religión racional y privada, y que influiría en la decisión hegeliana de convertirse en un educador moral, al modo de Lessing.

\section{LA CRÍTICA DEL JOVEN HEGEl A LA SOLEDAD ONTOLÓGICA}

Hay que recordar el triplete de nociones que Hegel está articulando en el Fragmento de Tubinga, porque el "acercarse a Dios" juega de modo diferente en la religión popular, en la pública, o en la racional y privada. Respecto de la religión popular - Volksreligion - vale lo que se ha dicho, el sensus communis, el conjunto de valoraciones compartidas sobre lo conveniente, lo útil, lo bueno ${ }^{35}$, permite una articulación entre moralidad y tendencias, que es imposible para estos dos factores de modo aislado, separado. Si las tendencias separadas son erráticas, si la moralidad aislada, en su pureza, entra en pugna con el perfeccionamiento y promoción de lo humano en su integridad, la verdad, el concepto, la articulación de las dos, se da en un factor que no es subjetivo, sino un ámbito objetivado, la religión popular, la religión como saber compartido, que nace en las prácticas. Este es el sentido del "acercarse a Dios", que por otra parte permite a Hegel tomar postura frente al romanticismo. En efecto, Hegel es romántico en cuanto registra la fractura, la contradicción. Pero no lo es en el modo de una

33 Cfr.: Paredes, M. C., Génesis del concepto de verdad..., p. 43.

34 Kaufmann, W., "Hegel's Early Antitheological Phase", p., 6.

35 Choza, J., Los otros humanismos..., p. 105. 
confusión inmediata del todo con Dios. Hegel no es como Novalis, que siente y sabe del más allá, pero ya aquí; siente su familiaridad, su vecindad, es Novalis un amante de la Noche. Por ello, Hegel señala el carácter dinámico, procesual: "acercarse". "En Hegel hay un abandono, o un rechazo del ideal estético del romanticismo. Dicho ideal consiste en la confusión de Dios con la naturaleza. Se trata de un inmediatismo enfático, tedioso en definitiva" ${ }^{36}$. Acercarse, por el contrario, señala el carácter de experiencia para la conciencia de la mediación religiosa, el realizarse en un terreno de oscuridad, tentativo, no ajeno al error, sino que ha de admitirlo necesariamente. No se trata ya de la razón pura en su uso práctico, sino del conocimiento práctico.

Pero además la función mediadora de la religión popular permite la habitación humana del mundo, no la huída de él. La religión en cuanto institución inseparable del ejercicio de excelencias o virtudes que atienden a lo intersubjetivo, es un conectivo social de primera magnitud. La vivencia religiosa, que acentúa por ejemplo la compasión, no es compatible con el atomismo social, o el abandono del mundo. Esta vivencia religiosa tenía un significado vital muy fuerte para Hegel, pues formaba parte de la praxis pietatis del pietismo wurttenbergués en que fue educado. Se trataba de una praxis, no de un mero saber, o un ideal abstracto, sino en palabras de Hegel un "saber práctico", que exige de sus fieles el compromiso ético, la virtud social, la responsabilidad en el mundo, la bella eticidad - Sittlichkeit-que Hegel aprecia en la religión y la vida cultural de los griegos. Es indudable que su visión de la religión helénica está idealizada, por la visión neoclásica (Winckelmann, Goethe) y romántica (Herder, Lessing, Schiller) de Grecia. No obstante esta grecomanía, la religión como conectivo social permite una articulación de la moralidad en sentido kantiano con la situación socio-cultural concreta, es decir la conciliación imposible para Kant entre el ámbito de la moralidad con el de la antropología, el de lo absoluto con el de condicionado, el de lo puro con el de lo empírico. "El lugar privilegiado que la religión popular tiene en el Ensayo de Tubinga se hace comprensible como el instrumento que Hegel encuentra para solventar la necesidad de unificar las capacidades humanas, ahistóricas de suyo - como la phronêsis aristotélica-, con el carácter contingente y situado de lo humano. Unificación que en su sentido más profundo exige sentirse como en casa en el mundo"37. De aquí que Hegel comience a realizar una historia social y cultural de las religiones en los mundos griego, romano y judío, y constate el fenómeno de la privatización de la religión, esto es de abandono del mundo. Al realizar esta historia cultural de las religiones, Hegel constata una sustitución de la

36 Polo, L., Hegel y el posthegelianismo..., p. 178.

37 Goldstein, J. D., "Hegel's Conception of Human Nature in the "Tübingen Essay" of 1793”, Clio, Summer 2003, 32, 4, p. 449. 
religión popular o religión de la Sittlichkeit por la religión privada.

Pero este resultado era importante, no solo a efectos de comprensión de la religiosidad popular, sino que como habían mostrado Shaftsbury y Stewart, daba las claves para comprender el declive de las sociedades antiguas. Dicho con otras palabras, el estudio de los factores que propician la riqueza de las naciones está en íntima conexión con la relación entre moralidad y Sittlichkeit. De aquí el interés del joven Hegel por los economistas ingleses, y la incorporación a su trabajo de los temas jurídicos, económicos y políticos. Según Stewart la decadencia de las culturas antiguas se debió a la promulgación de leyes que intentaban fomentar la moralidad, en la forma de luchar contra la corrupción que se suponía se seguiría de la acumulación de riquezas por los particulares. Las configuraciones sociales modernas exigían por el contrario la extensión del comercio, la difusión de la riqueza. La bella moralidad de los griegos resultaba perdida definitivamente. Así las cosas, un romántico inglés como Shaftesbury tiene una fuerte "vivencia del desajuste, la conciencia dolorosa de que - al final - la intimidad subjetiva y el espacio público no terminan de encajar, de que la propia vida no se desarrolla en el mundo sin fricciones. Porque Shaftesbury, que había defendido la polite philosophy entendida como amalgama entre filosofía y sabiduría moral de la vida en perfecta continuidad con la buena crianza, comienza a dudar de que su proyecto de realización de la propia interioridad se aloje precisamente en el ámbito de las relaciones interpersonales"38.

El carácter dinámico de la síntesis de facultades lograda por el universal religioso, no sólo afecta a la vivencia psicológica, sino también a las formas de interacción social y a las de organización social, que son variables históricamente. Sucede que la marcha de la historia, o en términos hegelianos, "la marcha de la razón" ha producido nuevas formas de organización social, y por lo tanto nuevas reglas que entran en colisión con las acciones individuales. Es así como la emergencia de la religión pública, o en otros términos, la positivización del cristianismo, o su destino, en la Roma de los primeros cristianos, y su ulterior metamorfosis en el protestantismo - la pura religión racionalredundaría sobre las demás esferas culturales: la jurídica, la económica, etc. Pensar estos procesos, y su repercusión en la subjetividad, es el cometido que alienta a Hegel desde la redacción de El espíritu del cristianismo y su destino hasta las lecciones del periodo de Berlín. Por ello, no se puede pensar que este texto sea meramente crítico, ilustrado. "Hegel no se limita a sufrir la negación y la escisión que implica, sino que la eleva a estructura de lo pensable y de la realidad entendidos dinámicamente. La negación no es un evento sobrevenido ni un hecho desconcertante, con que tropieza, sino la entraña de su experiencia

38 Rodríguez Lluesma, C., Los modales de la pasión. Adam Smith y la sociedad comercial, Eunsa, Pamplona, 1997, p. 186. 
intelectual" 39 .

Como señaló Carmelo Lacorte para el tema de la religiosidad importa la redacción de El espíritu del cristianismo y su destino porque está en juego “aquello que para Hegel significa lo abstracto, o lo 'fijado'. En el caso de la positividad de la religión ya había aflorado una polémica que apuntaba contra el complejo de ceremonias y de ritos en los que se fija, positivizándose, la función activa del universal religioso" 40 . La positivización de un religión es su cristalización en un determinado número de preceptos y ceremonias que sustituyen o suplen lo auténticamente religioso, o a la religión de la Sittilichkeit como forma de vida. Tales preceptos y rituales tienen ahora valor universal para la comunidad, o en palabras de Giambattista Vico, lo que puede ser una fuerte expresión de vida en la religión popular, se normativiza en la religión pública, que es lo generado en este proceso de objetivación. Tal normativización es inseparable de un aparato de autoridad, a la que los individuos deben obediencia, y por lo tanto, las mismas reglas que constituyen tal tipo de sociedad, son las que inconscientemente dominan a los individuos que la constituyen. De aquí que Hegel comience a distinguir entre la "religión de Jesús" y la "religión cristiana", entre una religión de la Sittlichkeit, de una religión privada, que pone en marcha un proceso histórico imparable de privatización, con el subsiguiente atomismo social. Esta distinción tenía su correlato cultural, como se ha dicho, en el "vivir como cristianos" del pietismo. Además, tal distinción es pertinente frente a la tesis de Kaufmann, y permite acceder al sentido la religiosidad hegeliana.

En primer lugar su religiosidad ha de permitir una vivencia de sí no escindida. En segundo lugar, ha de impulsar no sólo a la perfección individual, sino comunitaria. Tal impulso y fuerza es el significado propio del acercarse a Dios, que era el centro de los pensamientos hegelianos por 1795. Este acercarse a Dios, es pues indisociable del re-establecimiento de una religiosidad de la Sittilichkeit. Si se combina este pensamiento hegeliano de juventud, con el poderoso influjo que en Alemania comenzaban a tener las ideas liberales de Stewart y las prerománticas de Shaftesbury, entonces se puede llegar a pensar en una interpretación gnóstica del liberalismo, en la nueva ciencia de la marcha de la razón en la historia, o en economía política como teodicea ${ }^{41}$. Pero esto no puede ser tratado aquí.

Hegel seguirá en estos años de juventud discerniendo su original sentido de religiosidad. El siguiente leit-motiv será el hacerse amigo de Dios, hijo de

39 Ibidem.

40 Lacarte, Il primo Hegel, p. 105.

41 Cfr.: Polo, L., Hegel y el posthegelianismo...; Milbank, J., Theory and Social Theory: beyond secular reason, Blackwell, Massachussets, 1990, 2006; O'Regan, C., The Heterodox Hegel, SUNY, New York, 1994. 
Dios, imagen de Dios. Estos motivos no son separables de su comprensión de la comunidad, de la Gemeinde, de la función del universal, en este caso, un universal religioso. Y el discernimiento se trenzará con la lectura de Eckhart y de algunos místicos alemanes, como Boehme. Según nos informa Rosenkranz "ya hacia el final del período suizo se encuentran entre los papeles de Hegel extractos del Meister Eckhart y Taulero, copiados de revistas" 42 . Es Eckhart el que habla de "tener en uno la realidad de Dios", la ymago, que no cabe traducir adecuadamente por Bild, por cuanto objetiva a dicha realidad. Ymago no es mera representación mental, sino ante todo, realidad subjetiva. Si se admite su valor de mera representación, entonces renacería la distancia, la separación respecto del objeto. Hegel siempre "se opuso a un planteamiento directo y abstracto del tema de Dios"43. Oposición que hemos constatado en su crítica a la Postulatenlehre, y que implica un tratamiento de lo divino no separado de la actividad subjetiva - acercarse- .

Claro está que el maestro Eckhart va a configurar una religiosidad interior y cercana al monofisismo. En un fragmento de lectura trascrito por Hegel durante el invierno de 1795/96, se aprecian esta impronta eckhartiana.

"Un hombre bueno es el hijo unigénito de Dios engendrado por el Padre desde la eternidad. No digo que todas las criaturas sean algo mínimo o que sean algo, sino que no son nada (nihil). Hay algo en las almas que no es creado ni creable; y esto es la racionalidad..." $"$.

La bondad humana se asocia al deus latens en la interioridad personal. Más, comparada con esta realidad divina, lo creado es nada. Ella es la que se desvela como auténtica realidad, pero en el fondo de lo creado. Lo insondable como identidad de lo creatural. Y es insondable porque es eterno e ingénito: no creado ni creable. Aquí no hay escisión alguna; la realidad de Dios en uno mismo. El sujeto se reconoce como en su sí mismo más propio en la scintilla Dei viviente en el fondo, en la profundidad personal. El monofisismo está aquí gestándose, como barruntándose, y por ello, en este mismo año, al redactar " $E l$ espíritu del Cristianismo, Hegel sostiene que la idea judía de Dios como señor y legislador está basada en 'un abismo infranqueable entre la esencia humana y la divina' (N 302, 304), a esto contrapone la relación de un hijo con el padre, poniendo de manifiesto una orientación que será característica de su dialéctica posterior, esto es, la de la inmanencia de lo finito en lo infinito"45.

42 Rosenkranz, K., G.W.F. Hegels Leben, Berlin 1844 (reimpresa en 1966), p. 102.

43 Polo, Hegel y el posthegelianismo..., p. 214.

44 EJ., p. 69.

45 Paredes Martín, $M^{a}$ del C., "La dialéctica de la positividad en el joven Hegel" en Paredes Martín, $\mathrm{M}^{\mathrm{a}}$ del C., (ed.), Política y religión en Hegel, Universidad de Salamanca, Salamanca, 1995, p. 141. 